\title{
A COMPREENSÃO DOS GESTORES DE ESCOLAS MUNICIPAIS RURAIS DE LONDRINA SOBRE A ATUAÇÃO DE ASSISTENTES SOCIAIS NA ÁREA DA EDUCAÇÃO
}

\author{
Claudia Neves da Silva \\ Universidade Estadual de Londrina \\ claudianevess@uel.br \\ Flávia Silva de Oliveira \\ Universidade Estadual de Londrina \\ flavia-12111@hotmail.com
}

\section{Resumo}

A escola é uma instituição em que se manifesta cotidianamente uma multiplicidade de situações vividas e trazidas por estudantes, docentes e familiares, como disputas, conflitos, amizades, angústias, fruto das condições materiais e subjetivas dos sujeitos. A partir desta constatação, surgiu o interesse de conhecer o ponto de vista dos gestores quanto à possibilidade de atuação do Serviço Social em uma instituição escolar, particularmente de instituições localizadas em 2 (dois) distritos rurais do Município de Londrina, com a finalidade de construir uma metodologia de intervenção a partir de suas expectativas. Assim, entre os anos de 2016 e 2018 foram feitas visitas às escolas públicas municipais localizadas nos distritos rurais e entrevistas com 4 (quatro) gestores dessas escolas, para atender a uma das etapas do Projeto de Extensão Serviço Social na área da Educação, vinculado ao Departamento de Serviço Social da Universidade Estadual de Londrina. O presente artigo tem por objetivo apresentar o resultado das entrevistas e a proposta de uma metodologia de intervenção do Serviço Social em escolas localizadas em regiões rurais.

Palavras-chave: Escola. Serviço Social. Educação. Atuação Profissional.

\section{THE UNDERSTANDING OF LONDRINA RURAL SCHOOL MANAGERS ON THE ACTION OF SOCIAL WORKS IN THE AREA OF EDUCATION}

Abstract

The school is an institution in which daily manifests itself a multiplicity of situations lived and brought by students, teachers and family, such as disputes, conflicts, friendships, anguishes, fruit of the material and subjective conditions of the subjects. From this finding, came the interest to know the point of view of managers regarding the possibility of Social Work in a school institution, particularly institutions located in 2 (two) rural districts of Londrina, with the purpose of building an intervention methodology based on their expectations. Thus, between 2016 and 2018 visits were made to municipal public schools located in rural districts and interviews with 4 (four) managers of these schools, to attend one of the stages of the Social Work Extension Project in the area of Education, linked to the Department of Social Work, State University of Londrina. This article aims to present the results of the interviews and the proposal of a methodology of intervention of Social Work in schools located in rural regions.

Keywords: Social Work. Education. Managers. Professional Performance.

\section{LA COMPRENSIÓN DE LOS GESTORES DE ESCUELAS MUNICIPALES RURALES DE LONDRINA SOBRE LA ACTUACIÓN DE TRABAJADORES SOCIALES EN EL ÁREA DE LA EDUCACIÓN}

\section{Resumen}

La escuela es una institución en la que diariamente se manifiesta una multiplicidad de situaciones vividas y traídas por estudiantes, maestros y familiares, como disputas, conflictos, amistades, angustias, fruto de las condiciones materiales y subjetivas de las asignaturas. De este hallazgo, surgió el interés de conocer el punto de vista de los gerentes con respecto a la posibilidad de Trabajo Social en una institución escolar, particularmente instituciones ubicadas en 2 (dos) distritos rurales de Londrina, con el propósito de construir una metodología de intervención basada en sus expectativas. Así, entre 2016 y 2018 se realizaron visitas a escuelas públicas municipales ubicadas en distritos rurales y entrevistas con 4 (cuatro) gerentes de estas escuelas, para asistir a una de las etapas del Proyecto de Extensión de Trabajo Social en el área de Educación, vinculada a la Departamento de Trabajo Social, Universidad Estatal de Londrina. Este artículo tiene como objetivo presentar los resultados de las entrevistas y la propuesta de una metodología de intervención de Trabajo Social en escuelas ubicadas en regiones rurales.

Palabras clave: Trabajo Social. Educación. Los Gestores. Actuación Profesional. 
A compreensão dos gestores de Escolas Municipais Rurais de Londrina sobre a atuação de Assistentes Sociais na área da Educação

\section{INTRODUÇÃO}

A escola é uma instituição em que se configura uma multiplicidade de situações provocadas pelas condições materiais e subjetivas de estudantes, professores e familiares, e que cotidianamente se manifestam neste espaço acadêmico, como conflitos, disputas, amizades. É uma instituição que as crianças conhecem desde muito cedo e onde adolescentes e jovens manifestam suas ansiedades, expectativas e frustrações (ALMEIDA; SILVA, 2014, p. 47). Foi a partir dessa percepção do espaço escolar que surgiu o interesse de conhecer o ponto de vista dos gestores de escolas públicas estaduais e municipais localizadas no município de Londrina sobre a possibilidade de atuação de um assistente social em uma instituição escolar e, a partir de suas perspectivas, construir uma metodologia de intervenção no âmbito escolar.

A motivação para conhecermos o ponto de vista dos gestores se deve ao fato de que consideramos que a atuação do assistente social em instituições de ensino contribuirá para a ampliação do acesso dos estudantes à rede de serviços socioassistencias do território onde se localiza a escola, haja vista que muitos problemas que ocorrem em seu interior são decorrentes de situações vivenciadas fora dos muros escolares.

Entre o ano de 2014 e 2018 foi desenvolvido o Projeto de Extensão Serviço Social na área da Educação, vinculado ao Departamento de Serviço Social da Universidade Estadual de Londrina, cujo objetivo era estudar o fazer profissional dos assistentes sociais neste campo sócio ocupacional, verificar como o Serviço Social contribuiria para atuar junto às demandas na área da Educação e possibilitar aos estudantes do curso e profissionais da área conhecer a Política Social de Educação, o cotidiano escolar e seus sujeitos.

$\mathrm{Na}$ primeira etapa do projeto, foram realizadas entrevistas com os gestores e/ou pedagogos de escolas públicas estaduais, com a prévia autorização do Núcleo Regional de Educação de Londrina. As entrevistas tiveram por objetivo verificar como esses profissionais entendem a atuação de um assistente social em uma instituição escolar e, a partir de suas respostas, construir uma metodologia de intervenção do Serviço Social na área da Educação.

No ano de 2017, iniciou-se a segunda etapa do projeto de extensão, quando a aluna extensionista, sob orientação da coordenadora do projeto, realizou entrevistas com os gestores de escolas públicas municipais localizadas em 2 (dois) distritos rurais de Londrina, também com prévia autorização da Secretaria Municipal de Educação de Londrina. Foram selecionadas para essa etapa 4 (quatro) escolas municipais rurais (ensino fundamental do $1^{\circ}$ ao $5^{\circ}$ ano) e os sujeitos definidos foram os gestores dessas unidades de ensino que aceitaram participar da pesquisa. 
A compreensão dos gestores de Escolas Municipais Rurais de Londrina sobre a atuação de Assistentes Sociais na área da Educação

Neste artigo temos por intenção apresentar - a partir de autores que se debruçaram sobre esta temática - as atividades do profissional do Serviço Social em instituições escolares e as expectativas dos gestores no que se refere à atuação do Serviço Social na área da Educação. A partir de suas considerações, verificar se há pertinência e necessidade da presença deste profissional nos espaços escolares e a possibilidade de colaborar na construção de uma Educação voltada para os interesses de estudantes e comunidade.

Da mesma forma, espera-se colaborar para a construção de uma metodologia de intervenção do Serviço Social na área da Educação e reforçar a luta para aprovação da lei que prevê a contratação deste profissional para atuar em instituições de ensino.

\section{A CONTRIBUIÇÃO DO SERVIÇO SOCIAL NA ÁREA DA EDUCAÇÃO: BREVES CONSIDERAÇÕES}

A Educação é uma política social garantida a todos indistintamente, conforme determina o Art. 205 da Constituição de 1988:

A educação, direito de todos e dever do Estado e da família, será promovida e incentivada com a colaboração da sociedade, visando ao pleno desenvolvimento da pessoa, seu preparo para o exercício da cidadania e sua qualificação para o trabalho (BRASIL, 1988).

E é de responsabilidade do Estado e da família, conforme preconiza a Lei de Diretrizes e Base da Educação Nacional em seu Art. $2^{\circ}$ :

A educação, dever da família e do Estado, inspirada nos princípios de liberdade e nos ideais de solidariedade humana, tem por finalidade o pleno desenvolvimento do educando, seu preparo para o exercício da cidadania e sua qualificação para o trabalho (BRASIL, 1996).

Mas, para que a educação formal/escolarizada atinja seus objetivos, é preciso destacar que ela vai além da relação professor e estudante, porque é o resultado das relações que se estabelecem em uma dada sociedade, apresentando-se como um campo em que grupos sociais buscam legitimar e reproduzir suas ideias, ou seja, é um processo de socialização historicamente produzida e reproduzida conforme os interesses e necessidades dos grupos e classe sociais usualmente divergentes

[...] de um lado há os que querem impor e manter o consenso e a harmonia social por meio de uma educação passiva, que reproduz valores e ideias dos grupos dominantes, e por outro há os que buscam a formação de saberes e 
A compreensão dos gestores de Escolas Municipais Rurais de Londrina sobre a atuação de Assistentes Sociais na área da Educação

práticas que provoquem rupturas na produção e reprodução das condições materiais e culturais de existência, estabelecendo, desta forma, relações que se pautam na igualdade de condições entre os "desiguais". (ALMEIDA; SILVA, 2014, p. 50)

Neste sentido, o ato educativo também é político e pode contribuir para a reflexão sobre a realidade social, política, econômica e cultural em que os estudantes vivem e estabelecem suas relações - sociais, afetivas, profissionais. Enfim, a construção de uma sociedade em que os conflitos e as desigualdades sociais sejam superados ou ao menos enfraquecidos.

Schram e Carvalho (2011, p. 4) destacam que a educação é concebida como “instrumento à serviço da democratização, contribuindo pelas vivências comunitárias dos grupos sociais ... para formar pessoas participantes. A reforma da educação e a reforma da sociedade andam juntas, sendo parte do mesmo processo".

Os adolescentes e jovens que têm acesso à Educação formal/escolarizada, conhecendo as descobertas dos diversos campos do saber, têm condições de entender "a sociedade em que vivem e desenvolvam pensamentos e ações criativas que os levem a questionar e intervir para superar situações de exclusão, discriminação e violência de gênero e homofóbica.” (ALMEIDA; SILVA, 2014, p. 51) ${ }^{1}$.

Além disso, a escola que adota novas perspectivas pedagógicas possibilita aos estudantes trazerem para a sala de aula temas que estão em evidência na mídia e na própria comunidade.

Diante da necessidade de que a Educação formal suscite no educando a curiosidade e a vontade de ir além do que lhe é apresentado, mas ante uma realidade que negligencia o acesso ao saber, a intervenção do Serviço Social no âmbito escolar precisa ser entendida de forma crítica e vinculada com as expressões da questão social que se fazem presentes e, muitas vezes, mascaradas na escola.

A inserção do Serviço Social em instituições de ensino remonta ao início da profissão, década de 1930; a função do assistente social era atuar como o agente de ligação entre a escola e a família "era competência do Serviço Social atuar nas relações sociais no que se refere à sociabilidade das famílias com baixa renda e cuidados relacionados à moral, buscando adequá-los aos padrões comportamentais vinculados aos valores dominantes." (GONÇALVES, SILVA, 2011, p.7290), tendo em vista que a família era responsabilizada pelas atribulações e baixa aptidão dos alunos, cabendo ao profissional orientar a família e seus filhos/alunos para conseguir melhor ajustamento social. Conforme Iris de Lima Souza (2005, p.31): “o Serviço Social realizava

\footnotetext{
${ }^{1}$ Para aprofundamento sobre educação, sugerimos: FREIRE, Paulo. Educação como prática da liberdade. $7^{\mathrm{a}} \mathrm{ed}$. Rio de Janeiro: Paz e Terra, 1977; FREIRE, Paulo. Pedagogia do Oprimido. 39a ed. Rio de Janeiro, Paz e Terra, 1987.
} 
A compreensão dos gestores de Escolas Municipais Rurais de Londrina sobre a atuação de Assistentes Sociais na área da Educação

'Inquéritos Sociais' como diagnóstico da situação familiar, social e escolar dos alunos. O seu trabalho estava voltado, ainda, para revelar a personalidade do aluno aproveitando suas aptidões".

Se por um lado a presença de um profissional de Serviço Social na área da Educação já vem de longa data, por outro, essa presença ainda é tímida, não obstante a escola ser um importante - e complexo - equipamento social, considerando que neste espaço se apresentam diversificados dilemas, disputas e contrastes, e com potencial de minimizar, enfrentar e/ou superar os problemas particulares e sociais.

Nesse sentido, em seu agir profissional, o assistente social defronta-se com problemas que lhe exigem tomar decisões que levem em conta a situação social, cultural e econômica em que está inserido o estudante, seus familiares e os docentes, assim como lidar com os seus próprios valores, hábitos e atitudes.

Conforme Relly Amaral R. Vicente (2017, p.68):

O Serviço Social, como profissão atrelada principalmente às políticas sociais - e sendo a educação uma delas - insere-se em todas as modalidades educacionais, como por exemplo: educação infantil, educação especial e inclusiva, até a educação profissional, ensino superior e educação de adultos, além da socioeducação, e educação informal e comunitária. Sua prática profissional é dinâmica envolvendo, por exemplo, desde questões relacionadas ao planejamento educativo, atendimento aos alunos e familiares, movimentos sociais populares e de categorias profissionais, e ações de caráter informativo e formativo no âmbito político. Também se faz presente em órgão gestores como Secretarias e Núcleos de Educação, e no chamado "terceiro setor" - fenômeno que tem se ampliado na atual conjuntura globalizada e neoliberal, e se destacado enquanto instituição contratante dos assistentes sociais.

Em sua atuação junto aos discentes e professores o assistente social deve ultrapassar os portões da escola para atender às expectativas da família e da comunidade, comumente manifestadas no espaço escolar:

Se por um lado tal profissional pode criar meios para viabilizar o acesso aos direitos, tais como uma educação de qualidade para todos, por outro lado, o Serviço Social também pode ajudar a trazer a família para dentro da escola, atendendo a uma demanda e a um desejo antigo daqueles que hoje já se encontram envolvidos com o processo ensino-aprendizagem. (SILVA, 2012, p. 68).

Ao discutir sobre o trabalho do assistente social na área da Educação é importante considerar as mudanças que vêm acontecendo com a família, exigindo que os profissionais aprendam a lidar com as novas configurações, já que há uma multiplicidade de arranjos familiares, sendo necessário superar a ideia de que família seria constituída por um homem/pai, mulher/mãe e os filhos. O documento publicado pelo Conselho Federal de Serviço Social "Subsídios para a 
A compreensão dos gestores de Escolas Municipais Rurais de Londrina sobre a atuação de Assistentes Sociais na área da Educação

atuação dos assistentes sociais na política de educação", indica que o trabalho deste profissional não se limita ao estudante, abrange atividades

Junto às famílias, aos professores e professoras, aos demais trabalhadores e trabalhadoras da educação, aos gestores e gestoras dos estabelecimentos públicos e privados, aos/às profissionais e às redes que compõem as demais políticas sociais, às instâncias de controle social e aos movimentos sociais, ou seja, ações não só de caráter individual, mas também coletivo, administrativoorganizacional, de investigação, de articulação, de formação e capacitação profissional. (CFESS, 2014, p. 38)

Nesta perspectiva, podemos considerar que o objetivo do assistente social que exerce atividades no espaço educacional é viabilizar condições para que as crianças e adolescente possam ter acesso a uma educação formal e promover práticas socioeducativas que possam atender às necessidades e anseios do discente: "deste modo, acredita-se nas exequíveis contribuições que a presença do assistente social na escola representa para garantia de uma educação de qualidade, integral e que tenha como resultado o sucesso escolar do aluno". (SANTOS, 2012, p. 83).

A professor Eliana Martins (1999, p. 70) também ressalta alguns objetivos que devem orientar as ações do Serviço Social na área da Educação: contribuir para melhorar a situação socioeconômica das famílias,

Favorecer a abertura de canais de interferência dos sujeitos nos processo decisórios da escola (os conselhos de classe); Ampliar o acervo de informações e conhecimentos, a cerca do social na comunidade escolar; Estimular a vivência e o aprendizado do processo democrático no interior da escola e com a comunidade; Fortalecer as ações coletivas; Efetivar pesquisas que possam contribuir com a análise da realidade social dos alunos e de suas famílias; Maximizar a utilização dos recursos da comunidade [...].

O trabalho a ser desenvolvido pelo assistente social deve levar em conta as aspirações e necessidades da comunidade escolar, considerando a faixa etária dos envolvidos e seus anseios. No entanto, é importante a constante avaliação do trabalho, porque, como destaca Silva (2012), há artifícos que provocam a limitação da atividade do profissional de Serviço Social apenas aos estudantes, ocultando alguns riscos, tais como

a) a culpabilização dos estudantes b) reprodução de diagnósticos de agências mundiais sobre qual é o problema da educação/escola brasileira, que ora é o aluno, ora o professor, ora a metodologia e nunca a forma classista com que foi tratado esse campo em uma sociedade capitalista que quer desqualificar e dessignificar o que é bem público (SILVA, 2012, p. 17).

A atuação do Serviço Social na área da Educação exige dos profissionais o desafio de trabalharem em equipe para viabilizar o acesso às demais políticas sociais. Em vista disso, o 
A compreensão dos gestores de Escolas Municipais Rurais de Londrina sobre a atuação de Assistentes Sociais na área da Educação

profissional poderá atuar no campo educacional executando programas e projetos que subsidiem as políticas setoriais - saúde, habitação, assistência social - voltadas para as necessidades de estudantes, famílias e comunidade; além de desenvolver as atividades de interação grupal entre docentes e discentes, a comunidade escolar e a família, garantindo uma educação inclusiva.

A seguir, apresentaremos as considerações dos gestores quanto às possibilidades e contribuições do profissional do Serviço Social em instituições de ensino.

\section{A CONTRIBUIÇÃO DO SERVIÇO SOCIAL NA PERSPECTIVA DOS GESTORES DAS ESCOLAS MUNICIPAIS RURAIS}

No ano de 2017, visitamos 4 (quatro) escolas localizadas em 2 (dois) distritos rurais do Município de Londrina, com a finalidade de conhecer a realidade escolar e convidar os gestores a participarem do projeto de extensão, por meio de entrevistas sobre a necessidade da presença de um profissional do Serviço Social em instituições de ensino.

Nas entrevistas realizadas com os 4 (quatro) gestores, iniciamos com a segunite indagação: quais eram os principais problemas identificados no ambiente escolar. Os mesmos informaram que era o desemprego dos pais dos estudantes e a pouca participação dos responsáveis na vida escolar de seus filhos:

A não participação da família é um dos maiores problemas da nossa unidade. (Gestor 1)

O principal problema observado em nossa escola é a não participação das famílias na vida escolar dos filhos. (Gestor 2)

Os pais estão desempregados e com isso eles passam a não ter condições de subsidiar os filhos em todas as suas necessidades, uma delas é o próprio material escolar das crianças (Gestor 3)

Em uma pesquisa realizada no ano de 2012 junto a 4 (quatro) gestores de escolas estaduais de um município de pequeno porte localizado próximo a Londrina, estes também afirmaram que os principais problemas eram decorrentes de questões familiares:

...os problemas sociais identificados nas escolas estão relacionados ao ambiente familiar dos estudantes, como abandono material e afetivo, violência doméstica, uso abusivo de substâncias psicoativas, negligência e/ou desemprego dos responsáveis. Estas situações repercutiriam no seu comportamento e aprendizado (ALMEIDA; SILVA, p. 55). 
A compreensão dos gestores de Escolas Municipais Rurais de Londrina sobre a atuação de Assistentes Sociais na área da Educação

A família, não importa qual a sua configuração, geralmente transmite para a escola suas dificuldades, suas expectativas; se a família da criança ou do adolescente estiver com problemas de quaisquer naturezas, os reflexos se farão sentir no espaço escolar, já que:

[é o] Local onde os estudantes levam seus conflitos existentes fora da escola, explicitando as contradições socioeconômicas vivenciadas, o tráfico de drogas, violência familiar, gravidez na adolescência, trabalho infantil, dentre outros fenômenos sociais que se fazem presentes na realidade (PORTES et al., 2016, p. 5)

Os gestores afirmam a necessidade da participação da família na educação de seus filhos e nas atividades da escola. Todavia, a participação solicitada frequentemente limita-se a convocações dos responsáveis para comparecerem a reuniões onde será apresentada uma lista com queixas dos professores em relação aos seus filhos, em que somente o professor fala, sem incentivo para o debate (PORTES et al., 2016, p. 4). É uma situação que constatamos nas visitas às escolas públicas e nos contatos realizados com os gestores, pedagogos e professores, quando verificamos que a relação que estes estabelecem com as famílias dos estudantes por vezes se limita a reuniões para chamar a atenção sobre as baixas notas dos filhos ou para reclamar daqueles que têm problemas disciplinares e de aprendizagem.

Portanto, o profissional do Serviço Social "busca integrar o quadro de funcionários da escola a fim de trabalhar o emaranhado de questões que afligem a esfera educacional, efetivando a participação das famílias no processo de formação dos seus filhos" (COUTINHO; RIBEIRO; BARRETO, 2012, p. 99).

Para a construção de uma Educação que garanta o respeito e a valorização dos saberes e experiências dos estudantes e seus responsáveis, que possibilite questionar e combater a intolerância religiosa, o preconceito social, étnico e racial, a banalização da violência, é importante:

Propiciar espaços para a participação da comunidade escolar na dinâmica, atividades e decisões escolares. Pois, para integrar e possibilitar que os membros desta possam interagir com a mesma, tomando consciência do seu papel na gestão e no seu envolvimento, é necessário a abertura de espaços democráticos, dando voz às famílias e à comunidade escolar como um todo (PORTES et al. 2016, p.4).

Ademais, é necessário pensar estratégias de aproximação entre a equipe pedagógica, estudantes, família, professores e assistente sociais para desenvolver atividades que propiciem melhorias no processo ensino - aprendizagem. Neste sentido, conselhos escolares e de pais são 
A compreensão dos gestores de Escolas Municipais Rurais de Londrina sobre a atuação de Assistentes Sociais na área da Educação

espaços nos quais é possível discutir assuntos que permeiam tanto aspectos pedagógicos como sociais, culturais e políticos (PORTES et al. 2016, p. 4-5).

A partir do relato dos gestores sobre os problemas que adentram os muros escolares, indagamos quais seriam as atribuições dos profissionais do Serviço Social nas escolas. Estes informaram que:

$\mathrm{Na}$ escola, o assistente social nos ajudaria a conhecer a realidade familiar, o contexto em que a criança vive, de onde esta criança vem, como é a sua relação com seus pais, se há agressão física por parte da família com a criança (Gestor 1).

Este profissional ajudaria os professores a conversar com os pais e ver porque esta criança está com problemas no aprendizado. Muitas vezes o professor cobra muito do aluno na sala de aula, mas não sabe que na casa daquela criança não tem nem uma mesa para ela estudar, então assim fica difícil o professor lidar com 30/35 alunos e não saber ao menos quem são estes alunos (Gestor 2).

Sobre a contribuição do assistente social na escola, deve estar relacionada a contribuir com ações que tornem a educação como uma prática de inclusão, social, de formação da cidadania e emancipação dos sujeitos sociais. Ambos, tanto a escola como o Serviço social, trabalham diretamente com a educação, com a consciência, com a oportunidade de possibilitar as pessoas que se tornem conscientes e sujeitas de sua, própria história (Gestor 3).

Contudo, um dos gestores afirmou que o assistente social na instituição escolar não traria contribuições:

O assistente social não desenvolveria um bom trabalho, podendo atrapalhar o andamento da instituição. Além do mais, as escolas já contam com o trabalho da rede de proteção não necessitando deste profissional para compor a equipe escolar. (Gestor 4).

A partir da fala dos gestores verificamos que existe demanda para o profissional do Serviço Social. Em conformidade com texto já apresentado pela equipe do projeto, o trabalho do assistente social possibilitará a aproximação com equipamentos sociais do território em que está localizada a escola, como o CRAS (Centro Referência de Assistência Social), o CREAS (Centro de Referência Especializado em Assistência Social), a UBS (Unidade Básica de Saúde), o Conselho Tutelar, Ministério Público (PORTES et al. 2016, p. 6).

Quanto ao gestor que não se coloca favorável à presença de um profissional do Serviço Social em uma instituição escolar, consideramos que este posicionamento decorre do pouco conhecimento das atividades que o mesmo poderá desenvolver junto à comunidade escolar e seu entorno. Este desconhecimento provocou até pouco tempo uma rejeição de professores e pedagogos à inserção deste profissional no espaço escolar. Entretanto, com os programas sociais, 
A compreensão dos gestores de Escolas Municipais Rurais de Londrina sobre a atuação de Assistentes Sociais na área da Educação

principalmente o Bolsa-Família, houve uma aproximação da escola com o Centro de Referência de Assistência Social, gerando uma parceria entre os profissionais do CRAS e da escola em atividades junto aos estudantes e seus familiares (não cabe neste espaço a discussão desta parceria e suas consequências).

Como se pode verificar, o assistente social não ocuparia o cargo de outros profissionais ou interferiria nas ações da direção, do pedagogo ou do professor, tendo em vista que as atividades têm por finalidade principalmente a aproximação e mediação escola - família - rede de serviços-comunidade.

Os gestores também destacaram que uma das atribuições do profissional de Serviço Social seria o trabalho em rede:

O assistente social desenvolveria ações com os pais e alunos de cunho educativo. (Gestor 1)

O assistente social poderia estar realizando o encaminhamento e os contatos com os pais, familiares ou então os responsáveis pelos alunos, possibilitando bom rendimento dos estudantes na escola. (Gestor 2)

Acredito que o assistente social seria um ótimo profissional capacitado em realizar encaminhamentos para a rede de serviço. (Gestor 3)

De acordo com as respostas dos gestores, constatamos que o trabalho em rede é fundamental para o desenvolvimento de uma educação que leve em consideração os aspectos da realidade do estudante. Isso se torna mais claro quando indagados sobre como se dá a articulação da escola com a rede de serviços:

Temos uma boa pareceria entre a Unidade Básica de Saúde do distrito, CRAS, Igreja, CREAS (Gestor 1).

Temos um bom relacionameto principalmente com o Conselho Tutelar, CRAS e UBS (Gestor 2).

O conselho tutelar atende muito bem. Quando é preciso ser acionado, nos atendem com rapidez. O trabalho do posto de saúde também é muito bom para atender as crianças (Gestor 3).

Como se pode depreender do exposto, a escola é o local em que crianças, adolescentes e jovens compartilham suas dificuldades, expectativas, experiências e esperanças. Neste sentido, os profissionais não podem trabalhar de forma isolada, muito menos distante da comunidade. Diante de uma realidade complexa como é o espaço escolar, conhecer a situação dos que ali se encontram é necessário para realização de um trabalho em rede, visando uma ação para além da 
A compreensão dos gestores de Escolas Municipais Rurais de Londrina sobre a atuação de Assistentes Sociais na área da Educação

sala de aula e contribuindo desta forma, para o acesso e permanência na escola (PORTES at al. 2016).

A instituição escolar, que cotidianamente revela dificuldades socioeconômicas das famílias, gravidez na adolescência, baixo rendimento escolar, uso indevido de drogas lícitas e ilícitas, entre outros problemas, aumentou o interesse dos assistentes sociais pela área da Educação. E a partir das entrevistas realizadas com os gestores das escolas rurais de Londrina, verificamos que estes também consideram necessária e importante a presença deste profissional, porque ele conheceria a realidade do discente, acompanharia os familiares, faria a mediação na equipe de profissionais da escola, visitas domiciliares com o objetivo de conhecer os problemas que envolvem os estudantes e seus familiares.

Cabe às Secretarias Municipais e Estaduais de Educação a contratação de assistentes sociais que possam contribuir para trabalhar as questões que adentram os muros escolares; uma atuação que deverá se dar a partir de uma equipe multiprofissional - professores, pedagogos, direção e demais funcionários - além da mediação e incentivo para que a família, a rede de serviços e a comunidade em torno da escola participem na efetivação de uma educação que possibilite a permanência de adolescentes e jovens nos bancos escolares, ou seja, uma educação que respeite as diferenças históricas e culturais dos sujeitos.

\section{CONSIDERAÇÕES FINAIS}

As atividades previstas e realizadas na segunda etapa do projeto de extensão Serviço Social na área da Educação possibilitaram verificar as perspectivas dos gestores de 4 escolas rurais quanto à atuação do assistente social nessa área. Estes informaram que há situações que extrapolam as atividades pedagógicas e a presença de um assistente social propiciaria a busca de alternativas para lidar com questões que vão além dos muros escolares, como o acesso à rede de serviço socioassistencial no território onde se localiza a escola.

A inserção do profissional de Serviço Social na Educação é desafiadora, porque sua atuação deve estar articulada com a Política Social de Educação e a Política de Proteção à Criança e Adolescente, exercendo um papel de articulador dessas políticas no espaço escolar. Diante destas considerações, podemos afirmar que o projeto de extensão cumpriu seu objetivo, qual seja, conhecer a percepção dos gestores das escolas e a partir desta construir uma metodologia de intervenção do Serviço Social na área da Educação.

A Educação não suscita nos educandos uma visão crítica da sociedade em que vivem, muito menos para serem sujeitos de sua história, transformadores como diria Paulo Freire, 
A compreensão dos gestores de Escolas Municipais Rurais de Londrina sobre a atuação de Assistentes Sociais na área da Educação

apenas ensina e reforça para se adaptarem ao que está posto e determinado. E as condições para que os estudantes permaneçam na escola ultrapassam suas condições materias e subjetivas, porque estão relacionadas ao contexto social, cultural, econômico e político. Afinal, vivemos tempos em que o Estado reduz os recursos e investimentos nas políticas sociais - Educação, Saúde, Assistência Social, Habitação - e relega para o mercado, a sociedade civil e o terceiro setor suas obrigações, as quais estão devidamente expressas em leis.

\section{REFERÊNCIA}

ALMEIDA, J.N.; SILVA, C.N. A contribuição do Serviço Social na garantia da permanência dos estudantes na educação básica: um estudo a partir das escolas públicas estaduais do Município de Rolândia/PR. Revista Serviço Social em Revista. Londrina, Jul/Dez. 2014. p. 46-65

BRASIL. Constituição da República Federativa do Brasil de 1988. Disponível em: http://www.planalto.gov.br/ccivil 03/constituicao/constituicao.htm . Acesso em: 18 de dez 2018.

BRASIL. Lei no 9.394, de 20 de dezembro de 1996. Estabelece as Diretrizes e Bases da Educação Nacional. Disponível em: http://www.planalto.gov.br/ccivil 03/leis/L9394.htm . Acesso em: 18 de dez 2018.

BRASL, Presidência da República. Mensagem no 492, de 8 de outubro de 2019. Disponível em: http://www.planalto.gov.br/ccivil 03/ ato2019-2022/2019/msg/vet/VET-492.htm. Acesso em 31/10/2019

CFESS. Serviço Social na Educação. Grupo de estudos sobre o Serviço Social na Educação. Brasília: 2001.

CONSELHO FEDERAL DE SERVIÇO SOCIAL - CFESS. Subsídios para o debate sobre o serviço social na educação. Brasília: CFESS, 2011.

COUTINHO, Ângela Araújo; RIBEIRO, Mirian dos Santos; BARRETO, Valdineide Barauna. Serviço Social e Famílias: as Contribuições da Atuação Profissional do Serviço Social para Efetivação da Participação Familiar no Acompanhamento Educativo. Serviço Social na Educação: Teoria e Prática. Campinas: Papel Social, 2012. p. 88-109.

MARTINS, Eliana Bolorino Canteiro. O Serviço Social na área da Educação. Revista de Serviço Social e Realidade. v. 8, n 1. UNESP, Franca: São Paulo, 1999.

MARTINS, Eliana Bolorino Canteiro. O Serviço Social no âmbito da Política Educacional: dilemas e contribuições da profissão na perspectiva do projeto éticopolítico. Serviço Social na Educação: Teoria e Prática. Campinas: Papel Social, 2012. p. 33-54.

PIANA, Maria Cristina. A construção do perfil do assistente social no cenário educacional. São Paulo: Cultura Acadêmica, 2009. Disponível em: http://www.cairu.br/portal/arquivos/biblioteca/EBOOKS/SS/Construcao_do_perfil_do_ assistente_social.pdf. Acesso em: Acesso em: 10/10/2018. 
A compreensão dos gestores de Escolas Municipais Rurais de Londrina sobre a atuação de Assistentes Sociais na área da Educação

PORTES, Lorena Ferreira; SILVA, Claudia Neves da; SANA, Daniele Soares; OLIVEIRA, Flavia Silva de; PEIXOTO, Patrícia Aparecida. A contribuição do Serviço Social no espaço escolar: uma análise a partir da compreensão de gestores de escolas municipais e estaduais de Londrina- Pr. $15^{\circ}$ Congresso Brasileiro de Assistentes Sociais, anais, Olinda (PE) 5 a 9 de set de 2016. p. 1-11.

SANTOS, André Michel dos. As Práticas Socioeducativas do Assistente Social Inserido na Política de Educação. Serviço Social na Educação: Teoria e Prática. Campinas: Papel Social, 2012. p. 73-85.

SILVA, Claudia Neves da; PEIXOTO, Patrícia Aparecida; SLZ, Ana Paula Freitas. Serviço social na área de educação: demandas e possibilidades de atuação. Ebook: UNESP, 2016. p. 82-88. Disponível em:

SCHRAM, Sandra Cristina; CARVALHO, Marco Antônio Batista. O Pensar Educação em Paulo Freire: para uma pedagogia de mudanças. PARANÁ. Secretaria de Estado da Educação. Superintendência de Educação. $O$ professor PDE e os desafios da escola pública paranaense, 2007. Curitiba: SEED/PR., 2011. V.1. (Cadernos PDE). Disponível em: http://www.gestaoescolar.diaadia.pr.gov.br/modules/conteudo/conteudo.php?conte udo $=20$. Acesso em 02/01/2019.

SILVA, Marcela Mary José. O Lugar do Serviço Social na Educação. Serviço Social na Educação: Teoria e Prática. Campinas: Papel Social, 2012. p. 15-31

SOUZA, Iris de Lima. Serviço Social e Educação: uma questão em debate. Interface. Natal/RN, v.2 - n.1 - jan/jun 2005. Disponível em:

file:///C:/Users/silva/Documents/Extens $\% \mathrm{C} 3 \% \mathrm{~A} 3 \mathrm{o} /$ bibliografia $\% 20$ ss $\% 20$ na $\% 20$ educa $\% \mathrm{C} 3$ $\% \mathrm{~A} 7 \% \mathrm{C} 3 \% \mathrm{~A} 3 \mathrm{o} \% 20$ livros $\% 20 \mathrm{e} \% 20$ artigos $\% 20$ aninha/Servi $\% \mathrm{C} 3 \% \mathrm{~A} 7 \mathrm{o}-$ Social-e-

Educa $\%$ C3\%A7\%C3\%A3o-Uma-quest $\%$ C3\%A3o-em-debate.pdf. . Acesso em: 31/10/2019

VICENTE, Relly Amaral R. As condições objetivas de trabalho dos(as) assistentes socias inseridos na Política de Educação na Região Litorânea do Paraná. 2017. 165f. Programa de Pós-Graduação em Serviço Social e Política Social - Universidade Estadual de Londrina,Londrina, 2017.

Recebido em: 13/02/2019

Aceito em: 19/11/2019 